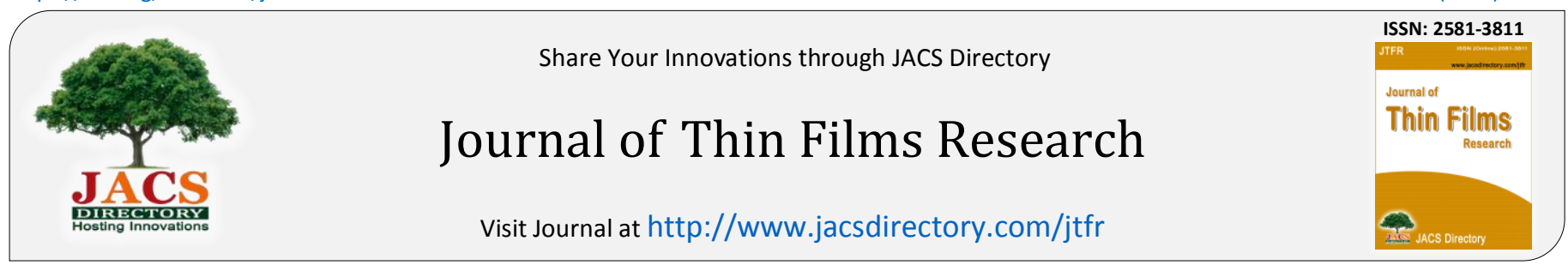

\title{
Effect of Sputtering Area Ratio of Gold/Alumina Target on Microstructure and Optical Absorption Properties of Au Nanoparticles dispersed in Amorphous Alumina Dielectric films
}

\author{
A. Belahmar ${ }^{1}$, A. Chouiyakh ${ }^{1, *}$, M. Fahoume ${ }^{2}$ \\ ${ }^{1}$ Department of Physics, Renewable Energy and Environment Laboratory, Faculty of Science, Ibn Tofail University, B.P.133, 14000 Kenitra, Morocco. \\ ${ }^{2}$ Department of Physics, Laboratory of Condensed Matter Physics, Faculty of Science, Ibn Tofail University, B.P.133, 14000 Kenitra, Morocco.
}

\section{A R T I C LE D E T A I L S}

\section{Article history:}

Received 01 July 2017

Accepted 09 September 2017

Available online 15 September 2017

\section{Keywords:}

$\mathrm{Au} / \mathrm{Al}_{2} \mathrm{O}_{3}$

AuNPs

SPR

Melting Point

\begin{abstract}
A B S T RA C T
Amorphous alumina films containing gold nanoparticles were grown by radio frequency (rf) magnetron sputtering technique, with a variation of area ratio of gold/Alumina target $\left(r_{\mathrm{Au}_{\mathrm{Al}} \mathrm{O}_{3}}\right)$. Effect of the gold content in the composite films on the microstructural and optical absorption have been investigated. From the X-ray diffraction (XRD) measurements, the texture coefficient, lattice parameter, grain size and strain were calculated and correlated with changing $r_{\mathrm{Au} / \mathrm{Al}_{2} \mathrm{O}_{3}}$. Contrary to the melting point of free metal cluster, it is found that melting point of gold nanoparticles embedded in amorphous alumina matrix is larger than the melting point of the corresponding bulk material, decreases with increasing size of particles. The surface plasmon resonance peak wavelength, volume fraction and size of gold nanoparticles were determined from the optical absorption spectra of the samples through the MaxwellGarnett effective model fitting, considering the size dependent mean free path limitation of free electrons. The peak wavelength of the surface plasmon resonance (SPR) was found to redshift from 500 $\mathrm{nm}$ to $558 \mathrm{~nm}$ and size increases from $2.2 \mathrm{~nm}$ to $5.8 \mathrm{~nm}$ when the $r_{A u / A l_{2} \mathrm{O}_{3}}$ increases from $1.3 \%$ to $2.6 \%$, and remain at the same wavelength for larger size.
\end{abstract}

\section{Introduction}

In the last decades, noble metal nanoparticles attracted considerable attention by scientific community, which is connected with their strong localized surface plasmon resonance (LSPR) that appears at optical frequencies. The (LSP) are quantized collective oscillations of conduction electrons against the positive ionic background in the presence of electromagnetic wave that can enhance and focus incident light to subwavelength dimension below the diffraction limit [1]. Surface plasmon resonance (SPR) technique is getting great attraction in sensor technology since it can be used for the detection of various physical, chemical and biological parameters [2-5]. The key parameter of such materials is often the position of the plasmon resonance peak that can be tuned over a wide spectral region by the NPs size and shape, their distance, by the surrounding dielectric environment of nanoparticles and, naturally by the metal type $[6,7]$. By tuning these parameters, the resonance frequency can be matched to any desired wavelength from visible to near-infrared region $[8,9]$. Therefore, by detecting the LSPR peak shift with refractive index/dielectric constant of surrounding medium, metal nanoparticles can be used as plasmonic sensors [6-9].

So far, various deposition techniques have been employed to fabricate $\mathrm{Au} / \mathrm{Al}_{2} \mathrm{O}_{3}$ thin films including ion implantation [10], sol-gel [11], Laser evaporation [12], and RF magnetron sputtering [13-16]. Among these techniques, RF magnetron sputtering takes the advantage of strong adhesion between film and substrate, large area deposition and low substrate temperature. However, various deposition parameters such as argon pressure, the variety of sputtering target, and sputtering power may influence the properties of the films. Furthermore, much attention has been paid to the changes of volume fraction of metal nanoparticles, and the composite of nanoparticles embedded in various matrices $\left(\mathrm{TiO}_{2}, \mathrm{ZnO}\right.$, BaTiO3, $\mathrm{SiO}_{2}$ and so on) for single metal dispersed composite films [1722]. In our previous work [16], we studied the effect of argon pressure on the concentration of gold nanoparticles dispersed in an alumina matrix. The present work focuses on the investigation of the influence of sputtering area ratio of $\mathrm{Au} / \mathrm{Al}_{2} \mathrm{O}_{3}$ for the target $\left(r_{\mathrm{Au} / \mathrm{Al}_{2} \mathrm{O}_{3}}\right)$ on the 
$\mathrm{Au}$ or $\mathrm{SiO}_{2}$ crystalline peak in the spectra, but there is a weak diffraction peak at around $38^{\circ}$ and a broad peak at around $64^{\circ}$, that corresponds to small gold nanoparticles embedded in amorphous alumina films. The

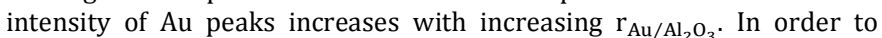
determine the phase structure, size and lattice parameter of AuNPs embedded in alumina films deposited at various $\mathrm{r}_{\mathrm{Au} / \mathrm{Al}_{2} \mathrm{O}_{3}}$, deconvolution procedure of the XRD patterns, where the details are reported elsewhere [23], were used assuming Voigt functions in order to obtain the peak position, intensity, preferential growth of the crystalline phases and the full width at half maximum.

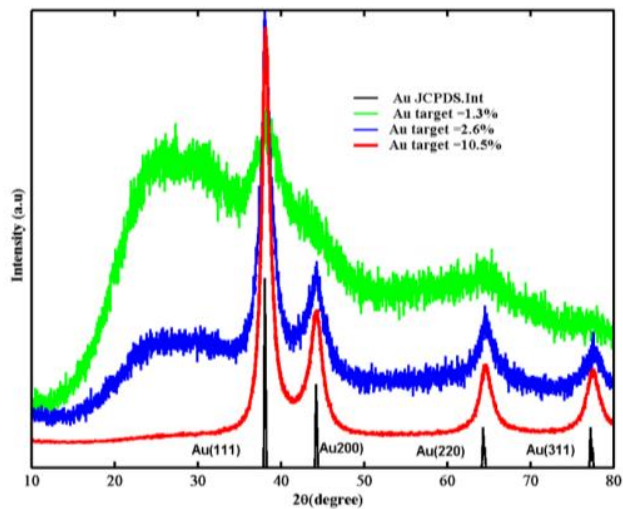

Fig. 1 X-ray diffractograms of $\mathrm{Au} / \mathrm{Al}_{2} \mathrm{O}_{3}$ nanocomposite thin films deposited at various gold/alumina surface ratio and JCPDS of gold thin films

The curve fitting XRD spectrum of A1 series is reported in Fig. 2. The diffraction peaks resulting from the fitting are attributed to the crystal planes of Au (111), Au (200) and Au (220). The peak positions are in agreement with the well-known data: JCPDS-04-0784 characteristic of the fcc cubic structure, indicating that the small gold particles should adopt a fcc-like structure. The samples deposited at $\mathrm{r}_{\mathrm{Au} / \mathrm{Al}_{2} \mathrm{O}_{3}}=2.6 \%$ and $\mathrm{r}_{\mathrm{Au} / \mathrm{Al}_{2} \mathrm{O}_{3}}=10.3 \%$ show four distinct peaks identical to the reference gold thin film. We can note that the peak around $2 \theta=26^{\circ}$, assigned to amorphous alumina, becomes broad and disappears when the $\mathrm{r}_{\mathrm{Au} / \mathrm{Al}_{2} \mathrm{O}_{3}}$ increases. This can be explained by the fact that the samples having a large gold/alumina surface ratio exhibit a metallic appearance.

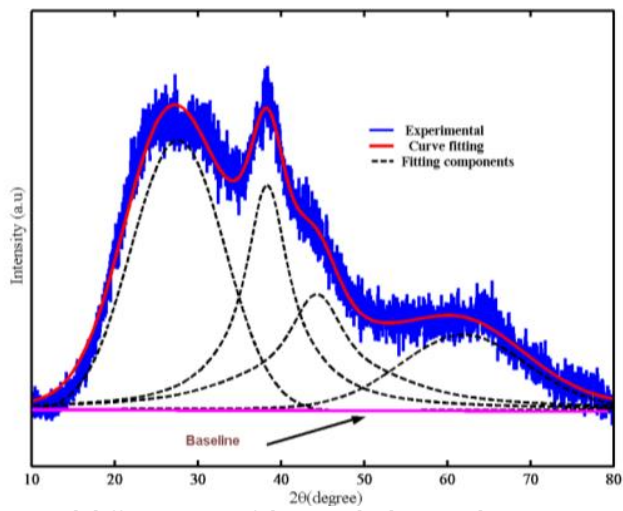

Fig. 2 Experimental diffractogram of the sample deposited at $\mathrm{r}_{\mathrm{Au} / \mathrm{Al}_{2} \mathrm{O}_{3}}=1.3 \%$ and their curve fitting where different pseudo-Voigt functions were taken into account

Quantitative information concerning the preferential crystal orientation can be obtained from the texture coefficient $\left(T_{c}\right)$, which is defined as in relation given by [24]:

$$
T_{c}(h k l)=\frac{I(h k l) / I_{0}(h k l)}{\frac{1}{n} \sum_{n} l(h k l) / I_{0}(h k l)}
$$

where $T_{c}(h k l)$ is the texture coefficient of the facet (hkl), $I(h k l)$ is the intensity of the $(h k l)$ reflection of the sample under analysis, $I_{0}(h k l)$ is the intensity of the $(h k l)$ reflection of a polycrystalline bulk sample and ' $n$ ' is the number of reflections taken into account.

If $T_{c}(h k l) \approx 1$ for all the considered $(h k l)$ planes then the particles are randomly oriented crystallites which are similar to the JCPDS references. If the values of $T_{c}(h k l)$ is greater than 1 , it indicates that the abundance of grain is formed in a given (h k l) direction. If $0<T_{c}(h k l)<1$ it indicates that there is a lack of grains in that given direction. As $T_{c}(h k l)$ increases, the preferential growth of the crystallites in the direction perpendicular to the [h k l] plane is greater. The texture coefficients calculated from their respective XRD peaks using Eq.(1) are shown in Table 1.
Table 1 Texture coefficient for four crystallographic planes of the deposited samples

\begin{tabular}{lllllll}
\hline $\begin{array}{l}\text { XRD peak } \\
(\mathrm{h} \mathrm{k} l)\end{array}$ & \multicolumn{2}{l}{ Intensity observed } & \multicolumn{4}{c}{$\begin{array}{c}\text { Texture Coefficient } \\
T_{c}(h k l)\end{array}$} \\
\cline { 2 - 7 } & $\mathrm{A}_{1}$ & $\mathrm{~A}_{2}$ & $\mathrm{~A}_{3}$ & $\mathrm{~A}_{1}$ & $\mathrm{~A}_{2}$ & $\mathrm{~A}_{3}$ \\
\hline $\mathrm{Au}(111)$ & 100.00 & 100.00 & 100.00 & 1.47 & 1.67 & 1.60 \\
$\mathrm{Au}(200)$ & 39.11 & 28.98 & 30.18 & 1.11 & 0.93 & 0.93 \\
$\mathrm{Au}(220)$ & 27.43 & 17.35 & 16.49 & 1.26 & 0.91 & 0.82 \\
$\mathrm{Au}(311)$ & 3.41 & 10.23 & 14.15 & 0.14 & 0.47 & 0.63 \\
\hline
\end{tabular}

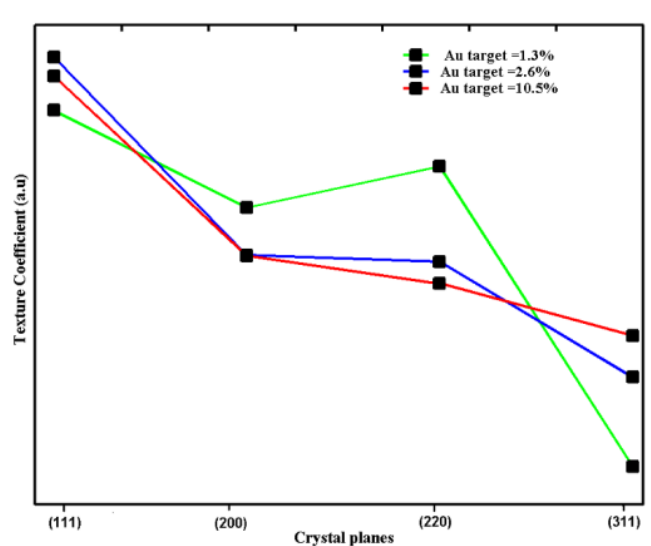

Fig. 3 Texture coefficient of $\mathrm{Au} / \mathrm{Al}_{2} \mathrm{O}_{3}$ nanocomposites thin films particles calculated from XRD pattern

Fig. 3 shows the gold/alumina ratio dependence of the texture coefficient for the (111), (200), (220), and (311) planes. The (111) plane is dominant. However, the Au crystallites have a texture structure along the Au (111). For this, all structural parameters will be calculated along this direction. The crystallite size was estimated from the Debye-Scherer's formula using the FWHM in radians of the Au (111) reflection:

$$
D=k \lambda / \beta \cdot \cos \theta_{B}
$$

where $\mathrm{k}$ is a constant (0.9), $\mathrm{D}$ is the crystallite size (in $\mathrm{nm}$ ), $\lambda$ is wavelength $(0.15406 \mathrm{~nm}), \beta$ is full width at half maximum (FWHM in radian) and $\theta_{\mathrm{B}}$ is the Bragg diffraction angle. The strain, $\varepsilon$ in the $\mathrm{Au} / \mathrm{Al}_{2} \mathrm{O}_{3}$ films are calculated from the well known Williamson-Hall relation [25]

$$
\varepsilon=\frac{\beta \cos \theta_{\mathrm{B}}-\frac{\lambda}{\mathrm{D}}}{4 \sin \theta_{\mathrm{B}}}
$$

The changes in the structural parameters of AuNPs are reported in Table 2. The lattice parameter and the grain size increases, while the strain decreases with increasing $\mathrm{r}_{\mathrm{Au} / \mathrm{Al}_{2} \mathrm{O}_{3}}$. The negative sign of the strain indicates that the strain is compressive. The increase in AuNPs sizes is obviously due to the increases in the gold concentration.

Table 2 Results of the curve fitting of the experimental diffractograms calculated from $\mathrm{Au}$ (111) reflections of the samples

\begin{tabular}{llllll}
\hline $\begin{array}{l}\text { Samples } \\
\text { Number }\end{array}$ & $\begin{array}{l}\text { Bragg's } \\
\text { angle } \\
2 \theta \text { (degree) }\end{array}$ & $\begin{array}{l}\text { FWHM } \\
\text { (degree) }\end{array}$ & $\begin{array}{l}\text { Lattice } \\
\text { parameter }(\AA)\end{array}$ & $\begin{array}{l}\text { Particle } \\
\text { size } \\
(\mathrm{nm})\end{array}$ & $\begin{array}{l}\text { Strain } \\
\left(\varepsilon \times 10^{-3}\right)\end{array}$ \\
\hline $1.3 \%$ & 38.57 & 8.07 & 4.039 & 1.04 & -11.2 \\
$2.6 \%$ & 38.36 & 2.65 & 4.060 & 3.17 & -3.7 \\
$10.5 \%$ & 38.12 & 1.14 & 4.085 & 7.34 & -1.6 \\
\hline
\end{tabular}

By increasing $\mathrm{r}_{\mathrm{Au} / \mathrm{Al}_{2} \mathrm{O}_{3}}$, the strain decreases, and takes the values $\left(-11.2 \times 10^{-3}\right),\left(-3.7 \times 10^{-3}\right)$ and $\left(-1.6 \times 10^{-3}\right)$ for the $A_{1}, A_{2}$ and $A_{3}$ series respectively, implying that these series are contracted during the sputtering process.

Young's modulus is one of the most fundamental parameter to depict the elasticity of a given material. It determines the basic elastic deformation capacity of a structure under a bear load. When the diameter of nanocrystals is in the scale of several nanometers, the Young's modulus is quite different from that of bulk. In order to determine elastic deformation capacity of nanocrystals, it is necessary to study the size dependent Young's modulus. Bhatt and Kumar [26] developed the relation to study the size and shape dependence of Young modulus of nanomaterials, which can be written as follows:

$$
\frac{Y(D)}{Y(\infty)}=\left(1-\frac{N_{S}}{2 n}\right)
$$

The Young modulus of nanomaterials with size D is $(D), Y(\infty)$ is the elastic modulus of corresponding bulk material $(78 \mathrm{GPa}), N_{S}$ is the number 
of surface atoms and $n$ is the total number of atoms. The value of $\frac{N_{s}}{2 n}$ depends on the structure of the Nanomaterials. For spherical nanosolids its value may be given by [27]:

$$
\frac{N_{S}}{2 n}=\frac{2 d}{D}
$$

where $D$ is the diameter of spherical nanosolids and $d$ the diameter of the atom. For gold $(d=0.2884 \mathrm{~nm})$. The calculated values are given in Table 3.

Table 3 Young's modulus and melting temperature of calculated from $\mathrm{Au}$ (111) reflections of the samples

\begin{tabular}{lll}
\hline Samples Number & Young' modulus (GPa) & Melting Temperature $\left({ }^{\circ} \mathrm{C}\right)$ \\
\hline $\mathrm{A}_{1}$ & 34.92 & 1468 \\
$\mathrm{~A}_{2}$ & 63.84 & 1177 \\
$\mathrm{~A}_{3}$ & 71.88 & 1120 \\
\hline
\end{tabular}

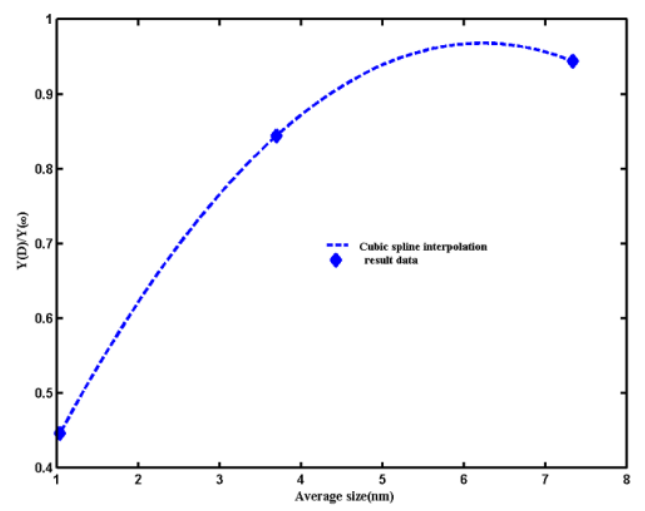

Fig. 4 size dependence of young's modulus of $\mathrm{Au} / \mathrm{Al}_{2} \mathrm{O}_{3}$

Fig. 4 presents the size dependent Young's modulus of Au-NPs. We can observe that Young's modulus decreases as the particle size decreases. It is clear from Fig. 4 that the size effect on Young's modulus is more and more obvious with the decrease in particle size. Its value increases from $34.92 \mathrm{GPa}$ to $71.88 \mathrm{GPa}$ when the size varies from $1.04 \mathrm{~nm}$ to $7.34 \mathrm{~nm}$.

Thermodynamic properties which are essential in utilizing nanomaterials in some fields applications such as microelectronics, nonlinear optics and solar energy, have garnered considerable attentions. Among these properties, melting point is the most practical property in NPs applications. It was reported in many works, for free standing NPs [28-30], that the melting point decreases with decreasing size of NPs. However, for the embedded NPs the melting point is not only related to NPs' size, structure and shape; but also affected by the embedding matrix. For some matrices, melting of the embedded NPs occurs in lower temperature than its bulk state, while it is possible for the same NPs to have superheating above the melting point in some other matrices [3135]. Qi et al. [36] have developed a new model to accounting for the size and shape dependent superheating of nanoparticles embedded in a matrix where the particle shape is considered by introducing a shape factor. Melting temperature $\mathrm{T}_{\mathrm{m}}$ of nanoparticles embedded in a matrix can be further written as [36]:

$$
T_{m}=T_{m b}\left[1-\frac{3}{2} \frac{d \alpha}{D}\left(1-\frac{T_{M}}{T_{m b}}\right)\right]
$$

where $\mathrm{T}_{\mathrm{M}}$ is the melting temperature of the matrix $\left(2054{ }^{\circ} \mathrm{C}\right.$ for alumina), $\mathrm{T}_{\mathrm{mb}}$ is the melting temperature of bulk pure metals $\left(1064{ }^{\circ} \mathrm{C}\right.$ for gold), $\mathrm{D}$ is the diameter of nanosolid, $d$ is the diameter of the atom and $\alpha$ is the shape factor. In our case, the nanoparticles are spherical, the form factor $\alpha$ is taken equal to 1 . The changes of melting temperature with size of god nanoparticles embedded in $\mathrm{Al}_{2} \mathrm{O}_{3}$ matrix were calculated using Eq.(6). The values are reported in Table 3 . The variation of the melting temperature with the gold particle size is reported in Fig. 5. We can note that the melting temperature of AuNPs embedded in amorphous alumina films decreases from $1468{ }^{\circ} \mathrm{C}$ to $1120^{\circ} \mathrm{C}$, when gold particle size increases from $1.04 \mathrm{~nm}$ to $7.34 \mathrm{~nm}$, indicating that particles with smaller size melt at higher temperature and not agree with the melting point of a free metal cluster size where it is well known to increase with its size. Another interesting observation is that the melting temperature values of all the samples remains above the melting point of bulk gold.

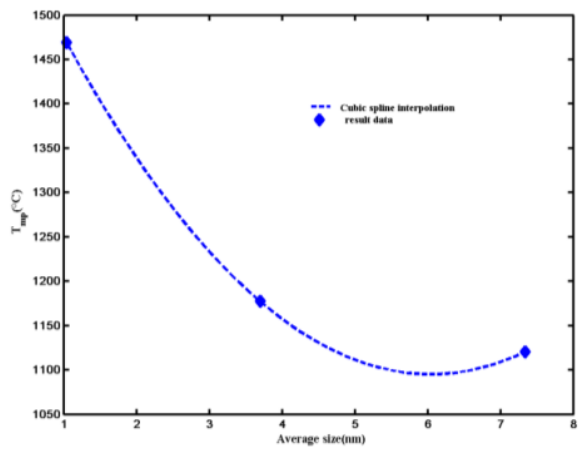

Fig. 5 Melting temperature of $\mathrm{Au} / \mathrm{Al}_{2} \mathrm{O}_{3}$ nanoparticles as a function of particle size

\subsection{Optical Characterization}

It is well known that the noble metal nanoparticles exhibit characteristic optical properties due to surface plasmon resonance of conduction electrons, which results in an absorption peak in the UV-Vis region. Fig. 6 shows the experimental optical absorbance spectra of $\mathrm{Au} / \mathrm{Al}_{2} \mathrm{O}_{3}$ three samples deposited at different $\mathrm{r}_{\mathrm{Au} / \mathrm{Al}_{2} \mathrm{O}_{3}}$ values. A very weak and large band absorption due to the surface plasmon resonance is observed for sample deposited at lower gold to alumina surface ratio $(1.3 \%)$. The broadening of the related SPR peak may be due to the mean free path effect as well as the influence of conduction electron collisions with particle surfaces [37]. With increasing $\mathrm{r}_{\mathrm{Au} / \mathrm{Al}_{2} \mathrm{O}_{3}}$ from $1.3 \%$ to $10.5 \%$, the SPR peak for the Au particles exhibited a significant redshift accompanying the narrowing and increase in intensity of the spectra.

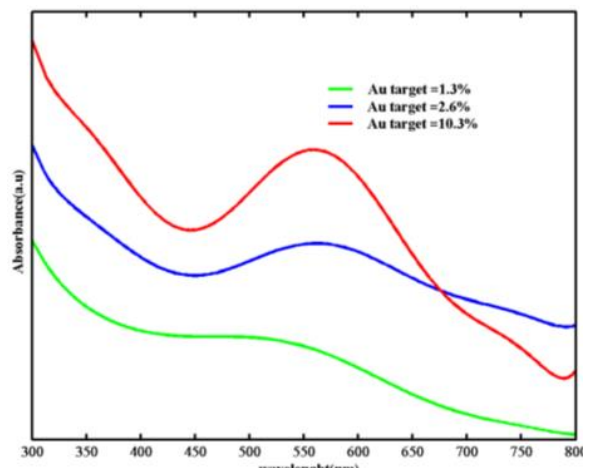

Fig. 6 Optical absorption spectra of $\mathrm{Au} / \mathrm{Al}_{2} \mathrm{O}_{3}$ composite thin films deposited at different $\mathrm{r}_{\mathrm{Au} / \mathrm{Al}_{2} \mathrm{O}_{3}}$

Using the well-known Maxwell-Garnett effective medium theory, the optical absorption coefficient $(\alpha)$ of the $\mathrm{Au} / \mathrm{Al}_{2} \mathrm{O}_{3}$ composite samples was calculated. M-G theory may be expressed as follow [38]:

$$
\alpha=\frac{4 \pi}{\lambda \sqrt{2}}\left[\left(\varepsilon_{e 1}^{2}+\varepsilon_{e 2}^{2}\right)^{1 / 2}-\varepsilon_{e 1}\right]^{1 / 2}
$$

where $\varepsilon_{e 1}$ and $\varepsilon_{e 2}$ are the real and imaginary parts of the effective dielectric function $\varepsilon_{\text {eff }}$ who satisfies the equation:

$$
\frac{\varepsilon_{e f f}-\varepsilon_{m}}{\varepsilon_{e f f}+\varepsilon_{m}}=f \frac{\varepsilon-\varepsilon_{m}}{\varepsilon+\varepsilon_{m}}
$$

where, $\varepsilon_{m}$ is the dielectric function of the matrix, $f$ and $\varepsilon$ are the volume fraction and dielectric function of the metallic particles. The dielectric function of Au was taken from the work of Palik [39]. The dependence of the metal dielectric function on the size of the particles is taken into account using the model presented by Hövel et al [40]:

$$
\varepsilon(\lambda, D)=\varepsilon^{b u l k}(\lambda)+\frac{\omega_{P}^{2}}{\omega^{2}+\mathrm{i} \omega \gamma_{b u l k}}-\frac{\omega_{P}^{2}}{\omega^{2}+\mathrm{i} \omega\left(\gamma_{b u l k}+2 A v_{F} / D\right)}
$$

where $\varepsilon^{\text {bulk }}$ is the bulk gold dielectric constant, $\omega_{P}, v_{F}$ and $\gamma_{\text {bulk }}$ being, the metal plasma frequency, the Fermi velocity and the electron scattering rates in the bulk respectively, and $\mathrm{A}$ is a phenomenological parameter including details of the scattering process. The values of these parameters used in our simulation are those cited in the work [16]. The simulation and the experimental plots are shown in Fig. 7-9. These fitting allowed us to evaluate, the gold particle size, the wavelength $\lambda_{\max }$ of the SPR band absorption spectra and Au volume fraction. The deduced parameters are summarized in Table 4. 


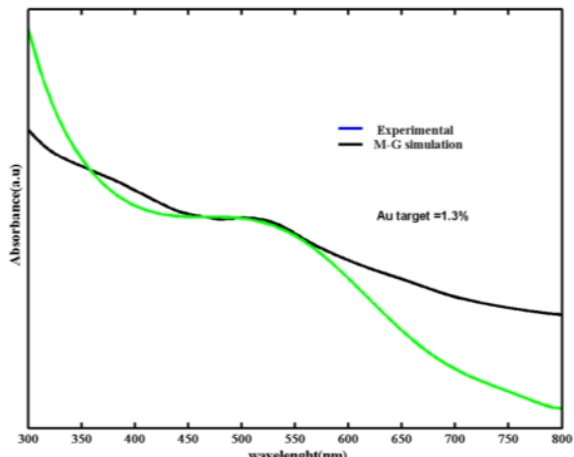

Fig. 7 Experimental and $\mathrm{M}-\mathrm{G}$ simulated optical absorption spectra for the composites films deposited at $\mathrm{r}_{\mathrm{Au} / \mathrm{Al}_{2} \mathrm{O}_{3}}=1.3 \%$

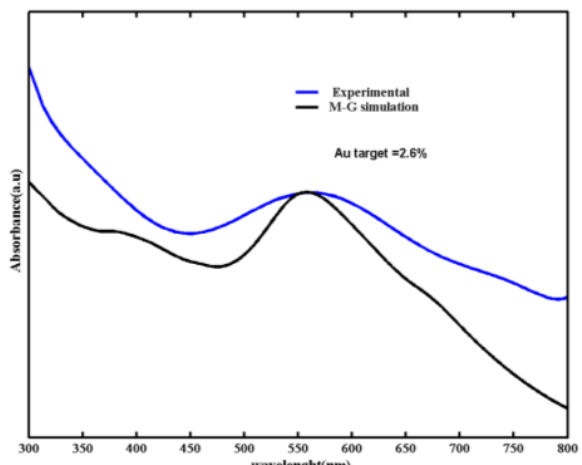

Fig. 8 Experimental and $M-G$ simulated optical absorption spectra for the composites films deposited at $\mathrm{r}_{\mathrm{Au} / \mathrm{Al}_{2} \mathrm{O}_{3}}=2.6 \%$

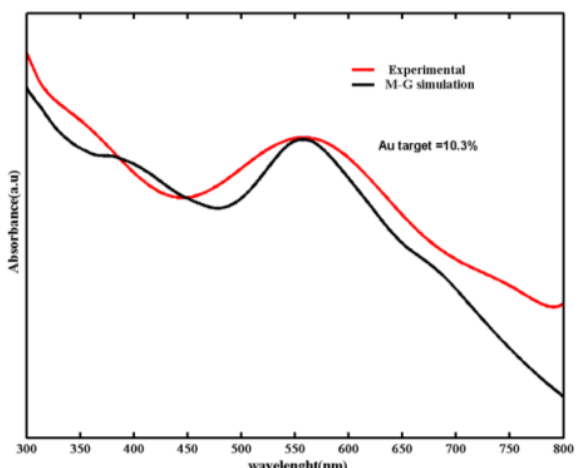

Fig. 9 Experimental and M-G simulated optical absorption spectra for the composites films deposited at $\mathrm{r}_{\mathrm{Au} / \mathrm{Al}_{2} \mathrm{O}_{3}}=10.3 \%$

Table 4 Plasmon peak, average size and concentration of the samples

\begin{tabular}{llll}
\hline Samples Number & SPR & Size $(\mathrm{nm})$ & Concentration $(\%)$ \\
\hline $\mathrm{A}_{1}$ & 500 & 2.2 & 7 \\
$\mathrm{~A}_{2}$ & 558 & 5.8 & 30 \\
$\mathrm{~A}_{3}$ & 558 & 7.8 & 46 \\
\hline
\end{tabular}

From the Table 4, we know that by increasing the area ratio of gold/alumina for the target, the size of AuNPs increases as well as the volume fraction of gold. The size varies from $2.2 \mathrm{~nm}$ to $7.8 \mathrm{~nm}$ when the concentration changed from $7 \%$ to $46 \%$ when the $\mathrm{r}_{\mathrm{Au} / \mathrm{Al}_{2} \mathrm{O}_{3}}$ increases from $1.3 \%$ to $10.5 \%$. While the resonance peak position shows a redshift as the Au content increased from 7 to $30 \mathrm{vol} \%$. Then, no obvious change in peak position is observed from 30 to $46 \mathrm{vol} \%$ of Au. Kreibig et al [37] reported that the size of Ag particles would also induce the shift of the SPR peak, but the position of the SPR peak was independent of particle sizes as the particle diameters were between $4 \mathrm{~nm}$ and $15 \mathrm{~nm}$. The independence of particle sizes on optical absorption of the colloid gold in photosensitive glasses was also reported as the particles were smaller than several hundred atoms $[41,42]$. This was interpreted as collisions of the conduction electrons with the particle surface, which reduced their effective mean free path, that is, the free path effect. The redshift of the SPR peak in the samples with 7-30 vol\% Au may be due to the size effect. The narrowed peak in the sample with $46 \mathrm{vol} \%$ of $\mathrm{Au}$ may be due to the enhanced intrinsic free electron oscillation inside metal particles [17].

\section{Conclusion}

In this work, nanocomposite $\mathrm{Au} / \mathrm{Al}_{2} \mathrm{O}_{3}$ thin films were synthesized by sputtering technique and characterised by XRD and optical absorption measurements. Increase in gold to alumina surface ratio give rise to an increases in the size and volume fraction of AuNPs. The lattice parameter, strain, young modulus, melting point and SPR peak position of AuNPs were determined and discussed. It is found that the melting point of gold nanoparticles dispersed in amorphous alumina films is larger than the melting point of the bulk gold material, and decreases with increasing size of AuNPs. Optical absorption spectra have been successfully explained by Maxwell-Garnett theory, taking into account of limited free path of conduction electrons. With increasing the volume fraction of Au content from $7 \%$ to $30 \%$, the position of the maximum of SPR band absorption of AuNPs exhibit a redshift from $500 \mathrm{~nm}$ to $558 \mathrm{~nm}$ and no obvious change was observed for the higher volume fraction up to $46 \%$, indicating that the peak position wavelength of the SPR is not sensitive to the particle size into the range included between $5.8 \mathrm{~nm}$ and $7.8 \mathrm{~nm}$.

\section{Acknowledgements}

We are grateful to Professor M.J.M. Gomes from the Centre of Physics, University of Minho, Portugal, for the experimental support.

\section{References}

[1] J.M. Pitarke, V.M. Silkin, E.V. Chulkov, P.M. Echenique, Theory of surface plasmons and surface-plasmon polaritons, Rep. Prog. Phys. 70 (2006) 1-78.

[2] W.L. Barnes, A. Dereux, T.W. Ebbesen, Surface plasmon subwavelength optics, Nature 424 (2003) 824-830.

[3] J. Homola, S.S. Yee, G. Gauglitz, Surface plasmon resonance sensors: Review. Sens. Actuat. B 545 (1999) 3-15.

[4] S.K. Mishra, D. Kumari, B.D. Gupta, Surface plasmon resonance based fiber optic ammonia gas sensor using ITO and polyaniline, Sens. Actuat. B 171-172 (2012) 976-983.

[5] R.C. Jorgenson, S.S. Yee, A fiber-optic chemical sensor based on surface plasmon resonance, Sens. Actuat. B 12 (1993) 213-220.

[6] X. Lang, L. Qian, P. Guan, J. Zi, M. Chen, Localized surface plasmon resonance of nanoporous gold, Appl. Phys. Lett. 98 (2011) 093701- 093703.

[7] H. Chen, L. Shao, Q. Li, J. Wang, Gold nanorods and their plasmonic properties, Chem. Soc. Rev. 42 (2013) 2679-2724.

[8] K. Lance Kelly, E. Coronado, L.L. Zhao, G.C. Schatz, The optical properties of metal nanoparticles: the influence of size, shape and dielectric environment, J. Phys. Chem. B 107 (2003) 668-677.

[9] E.C. Dreaden, R.D. Near, T. Abdallah, M.H. Talaat, M.A. El-Sayed, Multimoda plasmon coupling in low symmetry gold nanoparticle pairs detected in surfaceenhanced Raman scattering, Appl. Phys.Lett. 98 (2011) 183115-183115.

[10] M. Ohkubo, N. Susuki, Morphology of small gold crystals formed inside sapphire by ion implantation, Philos. Mag. Lett. 57 (1988) 261-265.

[11] Y. Hosoya, T. Suga, T. Yanagawa, Y. Kurokawa, Linear and nonlinear optical properties of sol-gel-derived $\mathrm{Au}$ nanometer-particle-doped alumina, J. Appl. Phys. 81 (1997) 1475-1480.

12] B. Palpant, B. Prével, J. Lermé, E. Cottancin, M. Pellarin, M. Treilleux, et al, Optical properties of gold clusters in the size range 2-4 nm, Phys. Rev. B 57 (1998) 1963-1970.

[13] A. Belahmar, A. Chouiyakh, Influence of the fabrication conditions on the formation and properties of gold nanoparticles in alumina matrix produced by co-sputtering, Int. J. Nano. Mater. Sci. 3 (2014) 16-29.

[14] A. Belahmar, A. Chouiyakh, Sputtering synthesis and thermal annealing effect on gold nanoparticles in $\mathrm{Al}_{2} \mathrm{O}_{3}$ matrix, J. Nanosci. Tech. 2(2) (2016) 100-103.

15] A. Belahmar, A. Chouiyakh, Structural and optical study of Au nanoparticles incorporated in $\mathrm{Al}_{2} \mathrm{O}_{3}$ and $\mathrm{SiO}_{2}$ thin films grown by RF-sputtering, Int. J. Adv. Res. Comput. Sci. Softw. Eng. 6 (2016) 109-116.

[16] A. Belahmar, A. Chouiyakh, Size and concentration effects on surface plasmon resonance and Maxwell-Garnett absorption in RF-magnetron sputtered $\mathrm{Au} / \mathrm{Al}_{2} \mathrm{O}_{3}$ nanocomposite films, J. Thin Films Res. 1(1) (2017) 1-6.

[17] C.H. Zhao, J.L. Du, D.W. Huang, Y.Q. Li, J.H. Chen, W.Z. Li, Microstructure and strong optical absorption property of the $\mathrm{Ag} / \mathrm{Al}_{2} \mathrm{O}_{3}$ nano-films, J. Alloy. Compd 671 (2016) 419- 423.

[18] P.R. Ohodnicki Jr., C. Wang, S. Natesakhawat, J.P. Baltrus, T.D. Brown, In-situ and ex-situ characterization of $\mathrm{TiO}_{2}$ and Au nanoparticle incorporated $\mathrm{TiO}_{2}$ thin films for optical gas sensing at extreme temperatures, J. Appl. Phys. 111 (2011) 064320-064320.

[19] L. Giancaterini, C. Cantalini, M. Cittadini, M. Sturaro, M. Guglielmi, A. Martucci, et al., Au and Pt Nanoparticles effects on the optical and electrical gas sensing properties of Sol-Gel-Based ZnO thin film sensors, IEEE Sens. J. 15 (2015) 1068-1076.

[20] N.M. Lyadov, A.I. Gumarow, R.N. Kashapov, A.I. Noskov, V.F. Valeev, V.I Nuzhdin, et al., Structure and optical properties of $\mathrm{ZnO}$ with silver nanoparticles, Semiconductors 50 (2016) 43-49.

[21] Y. Yang, M. Nogami, J. Shi, H. Chen, Y. Liu, S. Qian, Self-assembled semiconductor capped metal composite nanopariticles embedded in $\mathrm{BaTiO}_{3}$ thin films for nonlinear optical applications, J. Mater. Chem. 13 (2003) 3026-3032. 
[22] C.H. Zhao, B.P. Zhang, S.J. Wang, P.P. Shang, S. Li, L.P. Yan, Microstructure and optical absorption property of the $\mathrm{Cu} / \mathrm{SiO}_{2}$ nano-films, Mater. Des. 32 (2011) 947-950.

[23] A. Belahmar, A. Chouiyakh, Effect of post-annealing on structural and optical properties of gold nanoparticles embedded in silica films grown by RFsputtering, Adv. Phys. Theory. Appl. 15 (2003) 38-46.

[24] C.S. Barret, T.B. Massalski, Structure of metals: crystallographic methods, Principles and Data, Pergamon Press: Oxford, UK, 1980, p.204.

[25] S. Das, T.L. Alford, Structural and optical properties of Ag-doped copper oxide thin films on polyethylene napthalate substrate prepared by low temperature microwave annealing, J. Appl.Phys.113 (2013) 244905- 244910.

[26] A. Bhatt, M. Kumar, Size and orientation dependence of elasticity of nanowire and nanofilm, Europhy. Lett. 99 (2012) 16001-16004.

[27] W.H. Qi, Size effect on melting temperature of nanosolids, Physica B 368 (2005) 46-50.

[28] M. Takagi, Electron-diffraction study of liquid-solid transition of thin metal films, Jour. Phy. Soc. Jap. 9 (1954) 359-363.

[29] R. Shidpour, H. Delavari, M. Vossoughi, Analytical model based on cohesive energy to indicate the edge and corner effects on melting temperature of metallic nanoparticles, Chem. Phys. 378 (2010) 14-18.

[30] W. Luo, W. Hu, S. Xiao, Size effect on the thermodynamic properties of silver nanoparticles, Jour. Phys. Chem. C 112 (2008) 2359-2369.

[31] H.W. Sheng, G. Ren, L.M. Peng, Z.Q. Hu, K. Lu, Epitaxial dependence of the melting behavior of in nanoparticles embedded in Al matrices, J. Mat. Res. 12 (1997) 119-123.
[32] H.W. Sheng, G. Ren, L.M. Peng, Z.Q. Hu, K. Lu, Superheating and melting-point depression of $\mathrm{Pb}$ nanoparticles embedded in $\mathrm{Al}$ matrices, Philos. Mag. Lett. 73 (1996) 179-186.

[33] F.G. Shi, Size dependent thermal vibrations and melting in nanocrystals, J. Mat Res. 9 (1994) 1307-1313.

[34] H. Saka, Y. Nishikawa, T. Imura, Melting temperature of In particles in an $\mathrm{Al}$ matrix, Philos. Mag. A 57 (1988) 895-906.

[35] K. Chattopadhyay, R. Goswami, Melting and superheating of metals and alloys, Prog. Mater. Sci. 42 (1998) 287-300.

[36] W.H. Qi, M.P. Wang, Size-and shape-dependent superheating of nanoparticles embedded in a matrix, Mat. Lett. 59 (2005) 2262-2266.

[37] U. Kreibig, C.V. Fragstein, The limitation of electron mean free path in small silver particles , Z. Phys. 224 (1969) 307-323

[38] J.C. Maxwell-Garnett, Colours in metal glasses and in metallic films, Philos. Trans. R. Soc. London. 203 (1904) 385-420.

[39] E.D. Palik, Handbook of optical constants of solids, Vols. I and II, Academic Press, New York, 1985.

[40] H. Hovel, S. Fritz, A. Hilger, U. Kreibig, M. Vollmer, Width of cluster plasmon resonances: bulk dielectric functions and chemical interface damping, Phy. Rev. B. 48 (1993) 18178-18188.

[41] G. Mie, Contributions to the optics of turbid media, Particularly of colloidal metal solutions, Ann. Phys. 25 (1908) 377-445.

[42] R.H. Doremus, Optical properties of small gold particles. J. Chem. Phys. 40 (1964) 2389-2396. 